\title{
Afectos y devenires trans. Aportes situados en el Alto Valle de Río Negro y Neuquén, Argentina
}

\author{
Transgender affection and becomings. Contributions from the Alto Valle region \\ of Río Negro and Neuquén, Argentina
}

\author{
Ana Matus \\ anamematus@gmail.com \\ Facultad de Derecho y Ciencias Sociales, Universidad \\ Nacional del Comahue, Argentina
}

Recepción: 19 Abril 2019

Aprobación: 29 Julio 2020

Publicación: 01 Marzo 2021

Cita sugerida: Matus, A. (2021). Afectos y devenires trans. Aportes situados en el Alto Valle de Río Negro y Neuquén, Argentina.

Descentrada, 5(1), e136. https://doi.org/10.24215/25457284e136

\begin{abstract}
Resumen: Este artículo busca caracterizar la situación afectiva de las personas trans en la región del Alto Valle de Río Negro y Neuquén, desde un relevamiento cuantitativo realizado durante el período 2017-2018. Con el objetivo de profundizar en la interrelación entre el contexto sociocultural e histórico y el nivel biográfico, seleccionamos tres casos de mujeres trans que se han asentado en General Roca-Fiske Menuco, para abordar con mayor profundidad sus trayectorias identitarias y afectivas. Los resultados nos muestran que asumir una identidad de género trans dificulta el establecimiento de vínculos amorosos, en sentido amplio. Concluimos que se trata de una forma específica de desigualdad social.
\end{abstract}

Palabras clave: Afectos, Identidades trans, Géneros, Sexualidad.

Abstract: This paper aims at characterizing the affective situation of transgender people from the Alto Valle region of Río Negro and Neuquén according to a quantitative survey carried out during 2017 and 2018. In order to study the interaction between socio-cultural and historical contexts and biographical levels more deeply, we selected the cases of three transgender women living in General Roca-Fiske Menuco. We analyzed their trajectories in connection to affection and in connection to identity in detail. The results show that assuming a transgender identity makes the creation of all sorts of love bonds difficult. We conclude that this is, in fact, a specific form of social inequality.

Keywords: Affection, Transgender identities, Gender, Sexuality.

\section{INTRODUCCIÓN}

En este trabajo exploramos las trayectorias de mujeres trans que se han asentado en General Roca-Fiske Menuco, ${ }^{1}$ caracterizando la compleja interrelación entre sus biografías y el contexto sociocultural e histórico específico en el que se han construido las tramas vinculares en las que participan. Organizamos nuestra tarea desde cuatro ejes. Luego de revisar las producciones en torno a lo trans (primer eje), abordamos la descripción de la situación de las personas trans en la región desde un relevamiento cuantitativo que formaliza la experiencia empírica de sus devenires (segundo eje). En el tercer apartado, mediante entrevistas, buscamos profundizar en los momentos biográficos indicados como significativos por mujeres trans. Se trata de los 
procesos de construcción de su identidad de género y el impacto que les ha supuesto esta construcción en su vida afectiva, tanto en relación con sus vínculos sexo afectivos como con las redes de afectos más amplias. Finalmente, arribamos a conclusiones que señalan, entre las consecuencias de asumir una identidad no normativa, cierta forma específica de desigualdad social —en especial para las mujeres trans - que hace foco en la dificultad de reconocimiento como parejas legítimas en las relaciones amorosas, así como en sus tramas afectivas más amplias.

Para el presente artículo, nos valemos de información obtenida a través del Relevamiento de población trans de la región de Río Negro y Neuquén, y fuentes primarias tales como observaciones participantes y entrevistas biográficas.

\section{ACERCA DE LO TRANS ${ }^{2}$}

Desde la década del '90 hasta la actualidad, es posible rastrear una extensa bibliografía sobre las cuestiones trans, que progresivamente fue constituyendo un efervescente campo de estudios académicos. En ella, se problematiza la universalidad de las subjetividades e identidades de género construidas desde visiones binarias y esencialistas, que son consideradas como propias de la modernidad (Balzer, 2010; Biglia y Lloret, 2010; Missé y Coll-Planas, 2010; Pérez Fernández-Figares, 2010; Ramírez Guzmán, 2014; Suess, 2010; Fausto Sterling, 2006; Butler, 1997, 2007, 2010). Resulta ineludible, en esta revisión, integrar las producciones del activismo político y académico trans que se ubica principalmente en Estados Unidos, y que fue delineando el desarrollo de un campo académico interdisciplinar (Stone, 1991; Prosser, 1998, Bornstein, 1997; Namaste, 2000; entre otros); sobre todo, la problematización contenida en "The Empire Strikes Back. A Posttranssexual Manifiesto" acerca de la constitución de una historia aprendida en que las personas trans se borran a sí mismas como tales, esto es, se "desvanecen" en la población normal y de esa manera se pierde la capacidad de representar las complejidades y ambigüedades de la experiencia vivida, de lo que supone narrarse trans (Stone, 1991).

En nuestro país, los estudios sobre identidades trans se van conformando como área de indagación a la par de la organización y el activismo político de referentes trans y de las agrupaciones que les nuclean. Activistas e intelectuales trans han sido pioneros en la reflexión sobre sus condiciones de vida. Han realizado contribuciones fundamentales al producir tempranamente conocimiento y teorizaciones que discuten los términos patologizantes desde las que son definidas sus subjetividades. Han intervenido e intervienen activamente en las luchas por la visibilización, el reconocimiento y la garantización de derechos por parte del Estado Argentino desde finales del siglo XX (Berkins, 2003, Cabral, 2014, 2014a).

Uno de los ejes que los trabajos relevados abordan es la relación de las personas trans con el ámbito de la Salud Pública y la denominada Salud Trans. Se analizan en ellos las condiciones de vulnerabilidad al VIH Sida y ETS, así como el proceso de implementación en Argentina del artículo $11^{\circ}$ de la Ley 26.743 (Fundación Huésped-ATTTA, 2013; Capicüa, 2014; Lazzaroni, 2015; Cutuli y Farji Neer; 2016).

A partir de la conversión de la Ciudad de Buenos Aires en territorio autónomo y en el marco de la redacción de un Código de Convivencia Urbana que reemplazaría los edictos policiales, se desarrollaron líneas de investigación que analizaron el rol de los medios de comunicación en la representación de la corporalidad travesti, así como la visibilidad política que comienzan a tener (Sabsay, 2011; Zambrini, 2013; Vázquez Haro, 2012). Otros trabajos analizan la representación de las personas trans en medios televisivos y gráficos (Medina, 2011).

Dentro de los estudios relacionados a este artículo, las investigaciones sobre la identidad de género trans como subversión del binarismo de género y las corporalidades trans en relación con la subjetividad, han sido ampliamente problematizadas (Fernández, 2003, 2004; Berkins, 2003; Berkins y Fernández, 2005; Berkins, 2007; Hiller, Mallimaci y Moreno, 2011; Zambrini, 2007; Cutuli, 2013). Así también, las formas de organización política de las agrupaciones de travestis (Cutuli, 2010,2012; Zambrini, 2012) y las modalidades 
en que se regulan y jerarquizan los estilos corporales generizados de las feminidades (Vacarezza, 2012, 2013, 2015).

La cuestión afectiva, la angustia de vivir en una suerte de incertidumbre de género y la cotidianeidad de personas que no se identifican con las identidades de género binarias (hombre/mujer) aparecen reflejadas en la línea de trabajos de no ficción y relatos biográficos (Sivori, 1998; Liso y Marina, 2013; Mansilla, 2013; Pavan, 2016; Sanzol, 2016). No asumimos que estas expresiones generalicen todas las experiencias afectivas, sino que en estos textos se pueden encontrar relatos de vulnerabilidad social, diferencias generacionales y la vivencia acerca de que una operación que "normalice" el cuerpo y lo adecue a un género, no disuelve mágicamente las tensiones de una subjetividad que expresa esa historia.

En el límite de las historias de vida y el relato novelado en primera persona, el trabajo de Duarte (2009) narra la inmersión -como cliente, a veces, como novio o amigo, otras- en la vida de las travestis que ejercen la prostitución en la zona de Constitución, en la ciudad de Buenos Aires; mientras que el de Solá (2016) es una novela que narra de manera descarnada las vidas de tres mujeres trans.

Los estudios sobre sexualidades resultan cruciales para avanzar en la problematización de la especificidad de los afectos trans. Se entenderá la sexualidad como un producto histórico, organizado socialmente (Weeks, 1993, 2012; Laqueur, 1994; Gagnon y Simon, 1973; Osborne y Guash, 2003) y que entreteje formas superpuestas y multidimensionales de poder que se inscriben en las vidas individuales y colectivas (Rubin, 1989; Morán Faúndes, Sgró Ruata y Vaggione, 2012; Ramírez Mateus, 2013; Cabral, 2014; Vergueiro cit. en Ramírez Guzmán, 2014). La sexualidad no es una dimensión particular, privada, autónoma e individual, sino que es, siempre y a la vez, social. Esta afirmación no supone desconocer, sin embargo, la centralidad que se le otorga a la sexualidad en la formación del yo en la modernidad, en la que aparece significada como el lugar de autodescubrimiento, de autoconocimiento y autorrealización (Illouz, 2009, 2010, 2014, 2016).

Desde la sociología, en Argentina y América Latina, se ha desarrollado un área de investigación sobre sexualidades, cuerpos y emociones que busca explicar el proceso social de estructuración de las sensibilidades a partir de la tensión entre la formación del individuo y el peso de las estructuras y sistemas sociales. Es posible rastrear en estas reflexiones la preocupación en torno al concepto de "cuerpo" en relación con lo social; así como por el estatus del cuerpo en el contexto capitalista actual (Pedraza Gómez, 2003; Pecheny, 2008; Figari y Scribano, 2009; D'hers y Galak, 2011; Jones, Figari y Barrón López, 2012; Fernández y Siqueira Peres, 2013). Los efectos sobre los cuerpos no normalizados, sobre los que actúa el Estado a través de la escuela primaria, son recopilados por las etnografías ofrecidas por López y Paz (2017).

\section{Escala Regional. El Alto Valle de Río Negro y Neuquén y la población trans}

Para conocer las características de las personas trans que se han asentado en la región, es necesario introducir la compleja interrelación entre sus biografías y el contexto geográfico, que supone elementos socioculturales e históricos específicos en los que se han construido las tramas vinculares en las que participan. En este sentido, se inicia este apartado con una breve caracterización de esto último, por entender que las cualidades del espacio no son escenario ni telón de fondo de las acciones recíprocas, sino que la organización territorial del Alto Valle es co-constitutiva de las interacciones que allí se generan, y tiene efectos particulares en las formas de socialización de las que vamos a ocuparnos (Simmel, 2014; Sabido Ramos y Zabludovsky Kuper, 2014).

Pensar en términos de tramas o entramados nos permite registrar los vínculos complejos con el espacio y entender la territorialidad con un sentido político. En otras palabras, partimos de pensar los limites espaciales como elementos sostenidos a significación por quienes allí habitan. 


\section{A. El Alto Valle}

Dentro de las regiones que se distinguen en la provincia de Río Negro, cada una con perfiles productivos particulares, el Alto Valle refiere a los 700 o 750 kilómetros cuadrados que se extienden por el departamento General Roca (Río Negro) y del departamento Confluencia (Neuquén). Las obras de riego -construidas desde 1916 por el Estado Nacional en sociedad con la empresa de ferrocarril- concluyen hacia 1930, lo que permitió la explotación frutícola. Se implementa un sistema de difusión de prácticas culturales. Prevalece el cultivo de la fruta de pepita (peras y manzanas) y se extienden las ramificaciones de la actividad frutícola: envases de madera, sidreras, galpones de empaque de fruta, industria metalmecánica (fábricas de insumos).

Actualmente, el Alto Valle es una región agroindustrial ligada al mercado de manzanas y peras para la exportación, con una importante concentración de la población en las ciudades principales: General Roca, Cipolletti, Regina, Allen y Cinco Saltos.

En la provincia de Río Negro, a las diversas regiones económicas se les superpone un mapa de poder político, cuyos centros están directamente relacionados con la estructura productiva diversificada que tiene la provincia. Viedma es el centro administrativo. Alto Valle, la región agroindustrial. La Zona Sur, dedicada a la ganadería extensiva, y Bariloche, un centro turístico internacional.

La provincia de Neuquén, en cambio, presenta una estructura productiva menos diversificada y más focalizada en la explotación hidrocarburífera y, en menor medida, hidroeléctrica. Esta estructura económica, basada en la producción y exportación de energía y recursos naturales no renovables, ha sido denominada de enclave debido a que la redistribución se da hacia afuera de los límites provinciales. Sus recursos provienen mayoritariamente de las regalías hidrocarburíferas, así como del régimen de coparticipación federal y el crecimiento del sector de servicios.

En Neuquén, el centro político está asentado en el departamento Confluencia, donde se encuentra la capital, dando lugar a un esquema centralizado de poder.

\section{B. Relevamiento de la Población Trans en Río Negro y Neuquén, Argentina. ${ }^{3}$}

¿Cómo conocer acerca de las personas que se autoperciben trans? ¿Cómo saber cuántas son, cómo viven, de qué manera acceden a la salud, a la educación y al amor, en el Alto Valle de Río Negro y Neuquén?

Para poder dar cuenta de esos interrogantes se hizo necesario diseñar una herramienta específica, que permitiera generar datos sobre un colectivo que, en general, está invisiblizado. Esto, debido a que ni las encuestas ni el censo (al menos hasta el 2010) incluyen formas de categorizar que contemplen la posibilidad de existencia de una identidad de género por fuera del binario hombre-mujer; por lo que se pierden los datos acerca de quienes no se han construido identitariamente en correlación con su sexo de asignación y se autoperciben ${ }^{4}$ trans. Los supuestos teóricos naturalizados en los diseños estadísticos dejan escapar información que se podría captar desde otras formas de conceptualizar los géneros.

Como afirma Bourdieu (2001), la categorización además de ser principio de construcción es un principio de evaluación de la realidad social. Las categorías son una creación arbitraria que no tiene más fundamento que la creación social y, sin embargo, nos parece la más natural e, incluso, nos proporciona el modelo de todos los cuerpos e identidades sociales.

El Relevamiento de la Población Trans de la región de Río Negro y Neuquén se gestó mediante un proceso de elaboración colectiva de un dispositivo de producción de datos que se construyó a partir de la realización de talleres participativos con organizaciones trans, personas trans independientes y personas aliadas de diversas disciplinas.

Los datos sociodemográficos presentados en el informe del Relevamiento nos permiten una caracterización de la población de referencia. ${ }^{5}$ 
Como veremos en el Cuadro 1, en Neuquén se observa una estructura de población que oscila entre los 17 y los 64 años, mientras que en Río Negro varía entre los 16 y los 49 años. Esto conduce a pensar que, en esta última, la población trans es más joven que en la primera. En términos generales, la mayor cantidad de población se concentra entre los 26 y los 40 años. Los grupos etarios con menor proporción son los de 15 y 20 años, y el de 56 años y más.

La baja proporción del primero puede estar relacionada con que coincide con la edad en la que hace pública su identidad de género (la mayoría lo hizo entre los 14 y los 20 años) y, en el segundo, a que la población trans no alcanza las edades adultas en las mismas proporciones que la población cis. Solo el 3\% tiene 56 años o más mientras que, de acuerdo al Censo 2010, a nivel nacional este porcentaje es aproximadamente del 19\%.

Como se señala en el Informe, a diferencia de las estructuras poblacionales tradicionales, se trata de un colectivo que no responde a los parámetros binarios más frecuentes de la estructura de población, es decir, a la división del sexo entre varón y mujer. En este sentido, podemos señalar que la estructura de la población trans encuestada está comprendida mayoritariamente por mujeres (78\%) y en menor medida por varones (22\%).

Cuadro 1. Población por grupos quincenales de edad según provincia

\begin{tabular}{l|r|r|r|r|r|r|}
\hline \multirow{2}{*}{ Edad } & \multicolumn{2}{|c|}{ Neuquén } & \multicolumn{2}{c|}{ Rio Negro } & \multicolumn{2}{c|}{ Total } \\
\cline { 2 - 8 } & cantidad & $\%$ & cantidad & $\%$ & cantidad & $\%$ \\
\hline
\end{tabular}

Fuente: Observatorio de Derechos Humanos de Neuquén en base a datos del Relevamiento Transformando Realidades 2017.

En relación con los procesos de construcción identitaria, la edad en la cual la mayoría de las personas encuestadas pudo contar acerca de su identidad de género autopercibida se sitúa entre los 10-19 años, siendo más frecuente en las mujeres trans entre los 10 y los 14 años. En cambio, para los varones trans la mayor proporción se sitúa entre los 15 y los 19 años. Quienes declararon haberlo contado entre los 5 y 9 años fueron, en todos los casos, mujeres (13\%). 
Gráfico 1. Edad en que pudo contar sobre su identidad de género

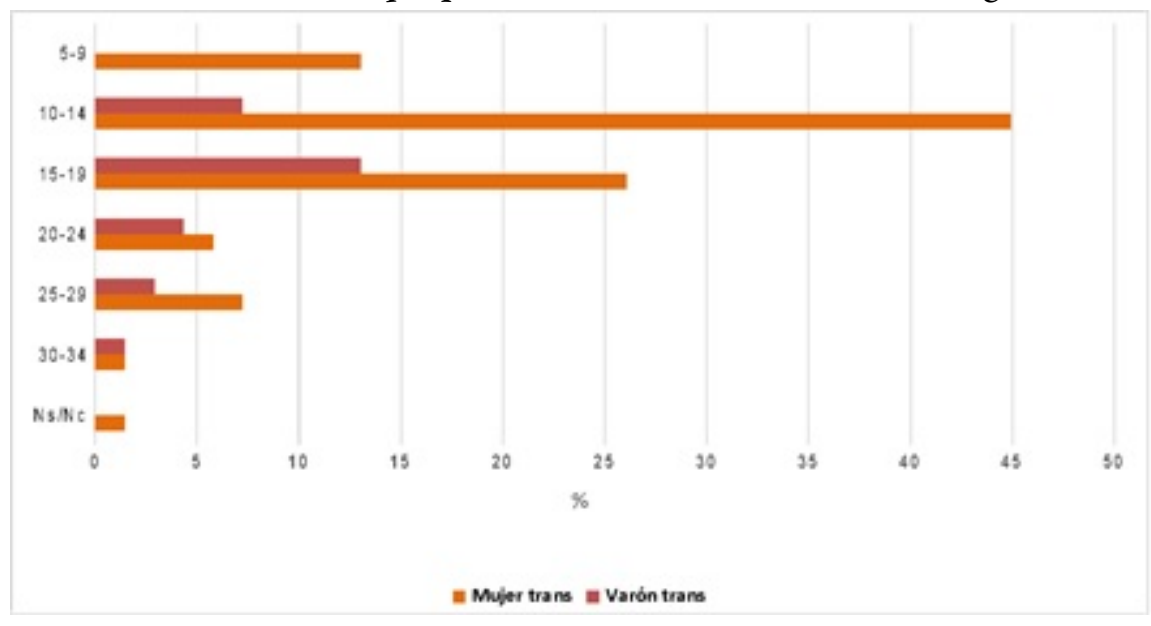

Fuente: Observatorio de Derechos Humanos de Neuquén en base a datos del Relevamiento Transformando Realidades 2017

Asumir la identidad de género autopercibida en el lugar de residencia fue, para la mayoría de las personas encuestadas, un proceso entre difícil y muy difícil (62\%). Si consideramos las edades en las que pudieron contar sobre su identidad autopercibida, cabe reconocer que, dentro de los marcos categoriales hegemónicos, se configuran como procesos difíciles de transitar, tanto en la esfera familiar como en los espacios de sociabilidades públicas diurnas.

Aun con las limitaciones que plantea una encuesta, en el relevamiento se intentó dar cuenta de las trayectorias afectivas de las personas trans, conocer cómo son sus vínculos amorosos, las relaciones filiales y conyugales que establecen y el impacto de asumir una identidad de género no normativa. Las respuestas muestran que más de la mitad de la población encuestada (el 56\%) tuvo dificultades para establecer vínculos amorosos debido a su identidad de género y algo más del $40 \%$ ha visto afectada su relación, cuando esta ya se había concretado.

Las dificultades mencionadas se relacionan, en la gran mayoría de los casos, con la mirada prejuiciosa y discriminatoria que permea a la sociedad en general y que se agudiza en las familias de sus compañeres. Hubo casos en que solo el ocultamiento parecía viable para sostener dichos vínculos. Incluso, aquelles que pasaban ${ }^{6}$ como personas cis, mencionaron que sus parejas no se permitieron avanzar con la relación al conocer su identidad de género y reaccionaron con actitudes de rechazo. Por último, hubo quienes señalaron que ante el temor a que alguna de estas dos situaciones se les presentara prefirieron no intentar ninguna vinculación sexo afectiva.

El $87 \%$ considera que su vida afectiva está conformada por sus amigues, lo que nos lleva a pensar que las redes de sostén más significativas son las construidas entre pares. 
Gráfico 2. Quiénes conforman su vida afectiva

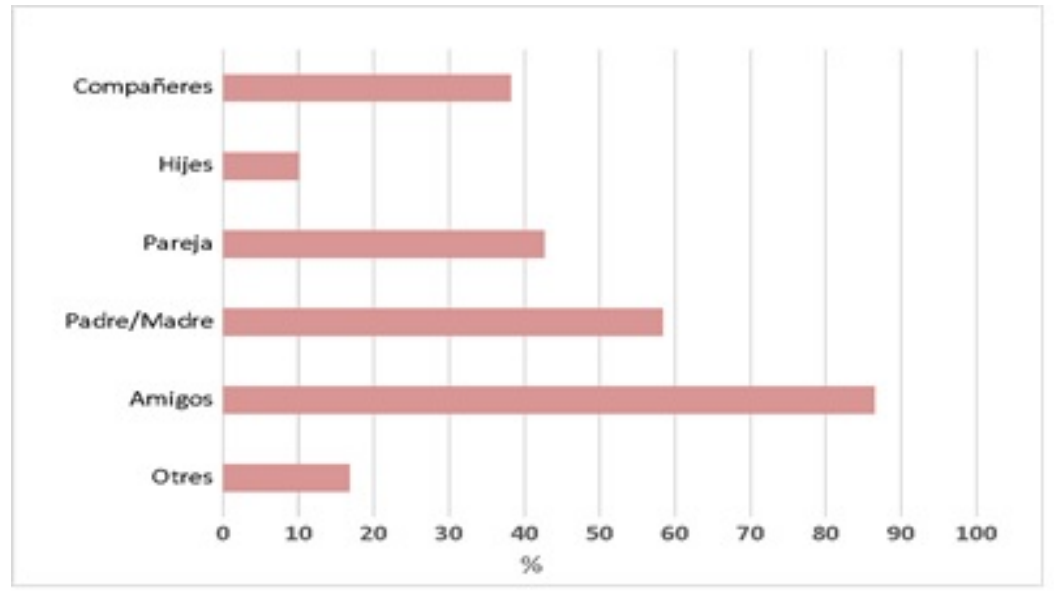

Fuente: Observatorio de Derechos Humanos de Neuquén en base a datos del Relevamiento Transformando Realidades 2017 (la categoría “amigos" está formulada sin uso de lenguaje inclusivo en la fuente original)

Finalmente, se les pidió a les encuestades que establecieran un orden según la importancia decreciente que les otorgaban a las diferentes temáticas trabajadas en la encuesta (de las que aquí hemos incorporado solo las que se relacionan con el planteo de nuestro objetivo). Las respuestas nos muestran, llamativamente, que un área considerada irrelevante como aspecto a incluir en las encuestas realizadas hasta el momento aparece como prioritaria cuando se les consulta a les protagonistas dándole participación en el diseño. Vemos que, después del trabajo, es la vida afectiva la que aparece como prioritaria. Atrás de ella se mencionan la salud médica, la vivienda, la economía, la educación, la vida colectiva y, por último, el acceso a la justicia.

Gráfico 3. Orden de prioridades

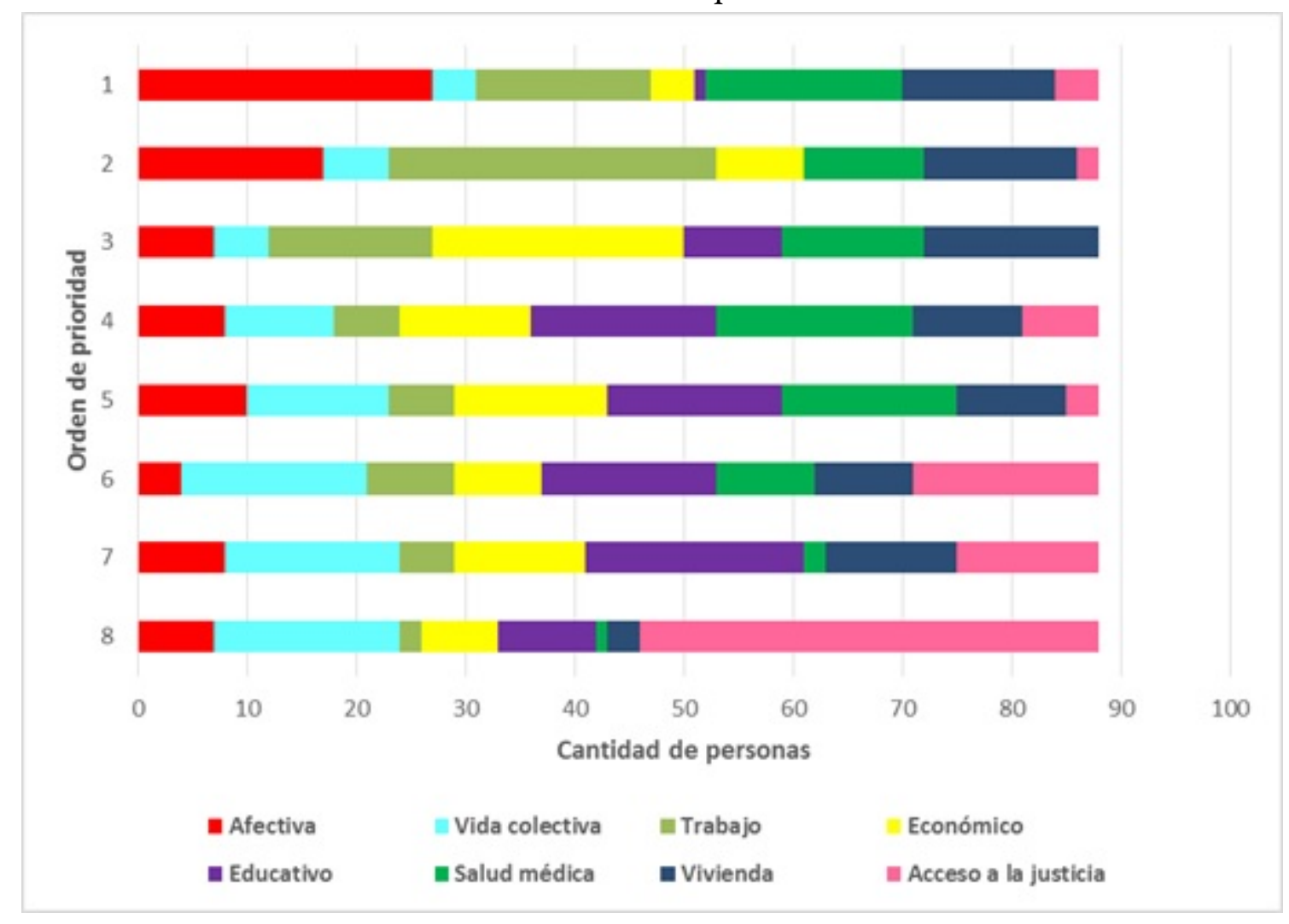

Fuente: Observatorio de Derechos Humanos de Neuquén en base a datos del Relevamiento Transformando Realidades 2017 
Podemos cerrar este apartado sintetizando nuestras reflexiones en torno a la inclusión de un bloque sobre "Afectos" (denominada por les participantes como "derecho a los afectos") y sobre la operación de categorización en general. Para quienes llevamos adelante este relevamiento, los afectos y las emociones no son cuestiones íntimas e individuales; por el contrario, las consideramos como prácticas culturales y sociales. También aquí, lo privado deviene asunto público.

\section{AfEctos y DEVENIRES TRANS}

En este apartado buscamos un retorno en clave cualitativa sobre momentos biográficos significativos señalados por las personas trans. Mediante entrevistas biográficas y observaciones participantes, buscamos ahondar en los procesos de construcción de su identidad trans y el impacto que les ha supuesto en su vida emocional, tanto en relación con sus vínculos sexo afectivos como con las redes de afectos más amplias. Registrar las vivencias de mujeres trans mediante técnicas cualitativas nos ha permitido visualizar en esos casos singulares cómo se entrelazan, en las posiciones individuales, las redes de condicionamientos, tanto interiores como exteriores (Lahire, 2016).

Los momentos que las entrevistadas identifican como significativos refieren al proceso de asumir una identidad trans como un punto de inflexión en relación con su vida afectiva y relacional. Se trataría, en términos de Giddens (1995), de momentos decisivos ${ }^{7}$ en los procesos de transición hacia la identidad autopercibida. También, en el desarrollo de las estrategias y redes afectivas que han sostenido en esos procesos sus vínculos de amistad, amorosos, laborales, de militancia.

En nuestro análisis, las diferentes trayectorias y prácticas son desplegadas en un contexto jurídico y social propio del tiempo histórico ${ }^{8}$ en el que se desarrollan.

Vamos a desagregar estos procesos complejos en secuencias que abordan: a) procesos identitarios; b) redes afectivas; c) vínculos sexo afectivos.

\section{A) Procesos identitarios}

El trabajo identitario, tal como lo concebimos siguiendo a Deaux y Martin (2003), supone dos niveles de contexto: categoría social y redes interpersonales. Así, vemos cómo en las personas entrevistadas se va configurando un modelo de identidad basado en el reconocimiento de un contexto cognitivo y representacional moldeado por la pertenencia categorial; y un contexto interpersonal basado en relaciones recíprocas específicas con otres:

Yo me definí como trans desde que tengo noción, o sea, no como trans, sino como... A mí me pasó algo muy raro, por ejemplo. Yo desde que tengo noción siempre me gustaron los nenes, y me gustaron las cosas de mujeres, obviamente, ropa de mujer, maquillaje, todo lo de mujer me llamaba la atención. Pero no sabía qué era (...) me miraba en el espejo llorando, pensando que era la única, porque no sabía lo que era, yo decía: ¿seré la única?, ¿esto me pasa a mi nada más?, porque nunca lo he visto (Entrevista a A., 26 años).

El médico me hizo análisis, me estudió, encontró lo que era el tema de las hormonas. Así que bueno, dio el positivo, de que yo tenía más hormonas femeninas que masculinas. El médico mismo me dijo “...fue una equivocación de la naturaleza. No sé qué pasó cuando estaba gestando tu madre. Algo se cruzó... una hormona o algo, que vos naciste con eso, que no es tuyo”. Me dice "ahora vamos a tratar de corregirlo" (Entrevista a R., 28 años).

La fluidez que adquieren estos procesos queda reflejada en los relatos de A. y R. Para la primera, las redes interpersonales en la vida cotidiana, el encuentro con otras mujeres trans, fue lo que le posibilitó poder darle un nombre a lo que le pasaba. Desde entonces, la grupalidad y los vínculos con personas que comparten la adscripción identitaria han ido reforzando esa asignación categorial, en los diversos entornos en que se mueve. 
En la historia de R., en cambio, la explicación se dio a partir de la autocategorización que ella hizo desde el modelo biomédico, que la lleva a concebir su deseo de una identidad femenina como una cuestión genética. Así, R. se vuelve inteligible para sí al definirse desde la adscripción a categorías identitarias tributarias del discurso biologicista.

Aparece una tercera situación, en la que se combinan los procesos intragrupales de vinculación con una práctica de militancia, que lleva a evaluaciones críticas de las categorías sociales, lo que da lugar a dinámicas de autodefinición más fluctuantes y disruptivas:

Lo que más me quedó marcado de mi infancia, es que yo siempre quise... me noté diferente a los demás (...). Muchas veces tuve que ser Z. [nombre masculino] y por ahí D. [nombre femenino] se escondía y salía Z. Pero el día que se concretó D. totalmente, físicamente, que dijo: 'acá estoy' fue cuando nací. Volví a nacer, hice frente al mundo y ya fueron otras cosas. Y ahí, cuando hice el [cambio]... ya no dolieron tanto los palos, no dolieron tanto los días de cárcel, no dolieron las pateaduras, no dolieron los reproches, no dolió más nada tanto, viste (...), y con la militancia aprendí que tengo derechos. En su momento, quizás sí los tenía, pero con otra identidad [con la cual] yo no me sentía representada, y se me desligó todo tipo de derecho (Entrevista a D., 45 años).

Estos procesos y su condición de posibilidad en tanto trayectorias identitarias aparecen habilitados por los entramados sociales, políticos, culturales en los cuales se entretejen. Lo que se reitera en estos y otros relatos es la convicción de que ser trans no se elige, que no hay espacio para desoír el deseo de construir una identidad que pueda ser leída, desde las categorías de percepción dominantes, como femenina (en los casos referidos).

\section{B) Redes afectivas}

En los fragmentos que siguen, vemos cómo se van entrelazando las experiencias de transitar el descubrimiento de una identidad que no se corresponde con el sexo asignado al nacer, con la consecuente falta de sostén de las redes familiares, para quienes la acción apropiada10 dentro del ordenamiento social heteronormativo y cis es el rechazo:

Eran los '90... No tenía el apoyo de nadie... Cuando yo le decía a mi padre, él agarraba y me pegaba, y me decía que yo era un hombre, que no era una mujer. Directamente, me decía, que yo estaba mal psicológicamente. Y yo le decía que no, que no estaba mal psicológicamente, que estaba decidida a transformar lo que era mi cuerpo (...) A mi mamá nunca le molestó que me vistiera con su ropa de mujer, ella me dejaba, como que callaba, pero sí me decía: “cuando vaya a llegar tu papá andá y cambiate”. Ella controlaba que no me encontrara mi papá, porque cuando mi papá me encontraba... ¡la paliza que me daba! Me dejaba el culo rojo de los cintazos: "que sos un varoncito" y "que sos un varoncito" (...). Mi papá trabajaba de albañil y mi mamá era ama de casa, murió cuando yo tenía ocho años, yo era chiquita (Entrevista a R., 28 años).

Las experiencias de D., y A., a pesar de la distancia entre sus edades, no difieren demasiado del relato de R.:

A los nueve años fue la peor paliza de mi vida, que recuerdo que me pegó mi papá, mi mamá, mi hermano. Así que esperé que se durmieran. Y como a las seis de la mañana salí corriendo por la calle y nunca volví. Llegué a la plaza y me acuerdo que un policía quería que yo le practicara... yo no sabía lo que era chupar una pija. Y el tipo quería forzarme y me dijo que me iba a llevar a la comisaría y me llevó ahí. Nadie me retiró. Y estuve ahí como tres días... pienso yo, ahora. Y cuando salí de ahí nadie me fue a buscar, así que agarré y me fui para la ruta y cuando quise acordar, con nueve años yo estaba en Bahía Blanca, viviendo en una plaza, en un pozo (Entrevista a D., 45 años).

Con las palizas terminaba toda rota. Porque no es que mi papá me pegaba y nada. No, me lastimaba toda. La boca, la nariz, chichones en la cabeza. Espantoso, era un horror. Un día que me estaba pegando tanto que mi mamá pensó que me había matado, se metió y la cagó a palos a ella. O sea, yo ya sabía que me tenía que ir, pero no sabía cómo, no sabía qué hacer, no sabía cómo vivir, ¿̇me entendés? (Entrevista a A., 25 años).

La violencia marca los cuerpos y la subjetividad de estas mujeres. Sin embargo, dentro de esas situaciones insoportables, ellas han puesto en acción fuentes microsociales de innovación y creatividad ${ }^{11}$ (Dalton, 2004) que, combinadas con sus prácticas habituales, les han permitido desarrollar estrategias de salida generando redes alternativas que las sostienen en lo afectivo. 


\section{C) Vínculos sexo afectivos}

En el orden de la sexualidad legítima (centrada en la reproducción heterosexual y cis), las mujeres trans aparecen devaluadas como posibles compañeras sexo afectivas. De diferentes maneras emerge, en el relato de sus itinerarios amorosos, el hecho de que asumir una identidad trans les ha supuesto habitar, a ellas y a sus compañeres, ${ }^{12}$ modos de existencia hondamente disímiles y estigmatizados:

Lo que pasa es que, como siempre, nosotras las trans somos vistas como objeto sexual, [parece que] lo único que sabemos es tener sexo las 24 horas. Pero la gente se olvida que comemos, dormimos, somos muy enamoradizas. Nos hacemos las fuertes y todo, y el eje central de todas nosotras - como todo ser humano, ¿no? - es el amor. Que, realmente, descreemos tanto porque todas las personas que se acercan, se acercan por interés. Porque, como somos generadoras de dinero y no medimos, entonces hay tipos que se acercan a nosotras por interés. Entonces, en algún momento nos cerramos al amor y no creemos en nada (...), he estado con personas, me he sentido bien, pero, bueno... Una confunde estar bien con amor, o acostumbramiento. O estar acompañada (Entrevista a D., 45 años).

Confirmando que los afectos son un elemento nodal en las configuraciones sociales, vemos cómo estos resultan centrales a la hora de diseñar estrategias de salida, esto es, reelaborar un vínculo amoroso como medio para irse de un hogar signado por el rechazo y la violencia:

De ese romance fue que ahí él me extrajo del barrio directamente, porque me enamoré de él y me dijo que me vaya a vivir con él. Tenía 40 años él y yo 19 años. Entonces yo ya estaba hasta las patas con él... ¡hasta las patas! (...). Él agarró y me dijo que me vaya a vivir con él y yo agarré todas mis cositas, hasta mi bicicleta, y me fui. Hice una historia tonta, dije que me iba a vivir a Buenos Aires (...). Bueno, él me regaló mi primera ropa de mujer, él me trató como una mujer todo el año que estuve juntada con él. Para él directamente yo siempre fui una mujer. Y yo seguí con mi evolución (Entrevista a R., 28 años).

El amor, los afectos y la deseabilidad aparecen como formas de reconocimiento. La aceptación, ser consideradas como personas valiosas, ser elegidas y compartir la esfera pública con sus parejas, son posibilidades que se distribuyen diferencialmente entre las personas cis y trans:

No hay mejor cosa que tener compañero (...). Entonces, no creo que necesite una vagina para que esté más, para que me acepte más. Como que él me aceptó así, y no hay nada que cambiar. Y las cosas que hay que cambiar lo hago porque a mí me parece; no porque a él le incomode o le moleste o mucho menos (Entrevista a A., 25 años).

En los relatos se menciona de manera recurrente lo que podemos denominar como "llamadas al orden por el grupo", esto es, las presiones e intervenciones sobre les compañeres sexo afectivos de las mujeres trans. Relevar estas situaciones permite poner el foco sobre las restricciones sociales que operan, la mayoría de las veces, de manera implícita. Las formas de sanción, en un contexto social intersubjetivo, muestran que las prácticas en general y las elecciones amorosas en particular, son siempre sociales. Estas acciones punitivas, como medios de control, van desde ataques a la autoimagen y la autoestima, hasta consecuencias materiales como la pérdida del trabajo o la ruptura de lazos familiares.

\section{Conclusiones, Pliegues, aperturas}

La escala regional elegida para este artículo se fundamenta en una perspectiva federal vinculada con el análisis situado en contextos locales singulares. De manera que apostamos a reelaborar una lógica argumentativa descentrada de las experiencias metropolitanas, tensionando la hegemonía del relato porteño. $^{13}$

Nos hemos abocado a la caracterización de la población de personas trans que se han asentado en el Alto Valle de Río Negro y Neuquén, a partir de los datos obtenidos a través del Relevamiento denominado TransFormando Realidades. Al construir un instrumento cuyas categorías relevan lo que no aparece como evidente, buscamos modificar las categorías de percepción que establecieron esa evidencia. Por ejemplo, acerca de qué datos son los que importan. 
Asimismo, conocer sobre los modos de vinculación afectiva que han sido posibles para la población trans del Alto Valle de Río Negro y Neuquén, mediante la inclusión de un bloque sobre Afectos, nos parece una apuesta para politizar la ilusión de neutralidad de las herramientas cuantitativas de construcción de datos, como reflejo de lo real. Recordemos, junto con Bourdieu (2001), que la lucha política se lleva a cabo por un trabajo de categorización, de explicitación y clasificación que representa un formidable poder social, el poder de hacer los grupos haciendo el sentido común, que consiste en hacer existir, en objetivar, hacer visible y decible aquello que estaba en estado de experiencia individual (como malestar o inquietud) y que, de esta manera, se hace público.

A través de las narraciones volcadas en las entrevistas biográficas y observaciones participantes realizadas, hemos constatado que, entre las mujeres trans, se despliega una pluralidad de prácticas de adscripción identitarias. Estas han estado vinculadas al reconocimiento de ciertos marcos categoriales disponibles en los contextos sociohistóricos en los que ellas han ido configurando modelos de identidad, desde los que se vuelven legibles para sí y para su entorno.

Otro elemento que ha incidido es el contexto interpersonal, basado en relaciones recíprocas con otras mujeres trans. Las redes interaccionales en la vida cotidiana, la grupalidad y los vínculos afectivos con personas que comparten la adscripción identitaria, refuerza esa asignación categorial.

Vimos, asimismo, cómo operan las categorías externas y los discursos vinculados al modelo biomédico en la construcción identitaria de otras mujeres trans. Ellas anclan su experiencia en una interpretación genética, que se sustenta en lo que podemos denominar el "paradigma del cuerpo equivocado", que supone que una vez reconocida la identidad autopercibida - se debe restituir la continuidad entre sexo-género-práctica sexual-deseo.

Desde un abordaje de las emociones de las mujeres trans y sus trayectorias afectivas, hemos constatado que asumir la identidad de género autopercibida en sus lugares de origen fue, para ellas, un proceso difícil. Fueron experiencias marcadas en todos los casos por el rechazo familiar y social. Para la mayoría de ellas, la vida afectiva está conformada actualmente por amigues, lo que nos confirma que las redes de sostén más significativas son las construidas entre pares.

Finalmente, es importante tener en cuenta el momento vital en que se encuentran quienes ofrecen las respuestas. En las trayectorias de algunas mujeres trans de más edad, se sucedieron revinculaciones con las familias de origen. A veces, encadenadas a la necesidad por parte de éstas de contar con el aporte económico que proveen las personas trans; pero también - y no menor- por las tareas de cuidados no remunerados que ellas realizan en las etapas de ancianidad de sus padres/madres.

Abordar los vínculos sexo afectivos de las mujeres trans supone profundizar en temas sensibles, en general no tematizados y, muy a menudo, banalizados. En sus relatos, aparecen regularmente situaciones que muestran que el reconocimiento amoroso y la aceptación social (del que un indicador sería el grado en que pueden compartir la esfera pública y relacional con sus parejas) son posibilidades que se distribuyen diferencialmente entre las personas cis y trans. Simultáneamente, reconocen que son buscadas y deseadas como objetos (ilícitos) de consumo sexual. Queda planteada la pregunta acerca de cómo comprender esta aparente contradicción entre deseo y agresión. Los modelos que naturalizan la jerarquía sexo-genérica en el interior de la pareja propician vínculos en los que algunas mujeres trans aceptan el ocultamiento, así como mantener económicamente a sus parejas, como el costo implícito de ser trans. Una suerte de gratitud hacia quien toma el riesgo social de estar con ellas. Constatamos que, en ciertas trayectorias, iniciar una relación de pareja aparece configurada como una estrategia de salida de hogares violentos. Paradójicamente, en otros casos, la elección contraria redunda en el mismo sentido: no tener pareja para evitar violencias potenciales, vivir de manera protegida y ahorrarse problemas; a la vez que ahorrarle humillaciones a esa posible pareja.

A través del recorrido realizado, hemos registrado las maneras en que asumir identidades no normativas conlleva consecuencias muy concretas para las personas trans en general y para las mujeres trans en particular, que las lleva a habitar posiciones sociales devaluadas. Si asumimos la necesidad de politizar nuestras 
investigaciones, entonces nuestra tarea como intelectuales comprometides, nos debe llevar a propiciar el reconocimiento de las personas trans como seres valiosos para ser amades (y no solo consumidas en su objetualización hipersexualizada), como una apuesta a ensayar prácticas que desmientan, destituyan y desconfiguren la lógica mercantil en las que aparecen como objetos de un deseo ilegítimo y vergonzante.

\section{ReFERENCIAS}

Balzer, C. (2010). Reflexiones etnológicas sobre la medicalización globalizada de las identidades trans a través del ejemplo de Brasil. En Missé, M. y Coll-Planas, G. (eds.) El género desordenado. Críticas en torno a la patologización de la transexualidad (pp. 81-96). Barcelona: Egales.

Berkins, L. (2003). Un itinerario político del travestismo. En Maffia, D. (comp.) Sexualidades migrantes. Género y transgénero (pp. 145-155). Buenos Aires: Librería de Mujeres y Feminaria.

Berkins, L. (comp.) (2007). Cumbia, copeteo y lágrimas. Informe nacional sobre la situación de travestis, transexuales y transgéneros. Buenos Aires: Asociación de Lucha por la Identidad Travesti-Transexual.

Berkins, L. y Fernandez J. (coords.) (2005). La gesta del nombre propio. Informe sobre la situación de la comunidad travesti en la Argentina. Buenos Aires: Ediciones Madres de Plaza de Mayo.

Biglia, B. y Lloret, I. (2010). Generando géneros y patologizando sujetos. En Missé, M. y Coll-Planas, G. (eds.) El género desordenado. Críticas en torno a la patologización de la transexualidad (pp. 211-227). Barcelona: Egales.

Bornstein, K. (1997). El género fuera de la ley. Acerca de hombres, mujeres y el resto de nosotrxs. Córdoba: Bocavulvaria.

Bourdieu, P. (2001). Describir y prescribir. En ¿Qué significa hablar? Economía de los intercambios lingüisticos (pp. 96 - 104). Madrid: Akal.

Butler, J. (1997). Sujetos de sexo / género / deseo. Feminaria, 19, 1-20.

Butler, J. (2007). El género en disputa. El feminismo y la subversión de la identidad. Barcelona: Paidós.

Butler, J. (2010). Transexualidad, Transformaciones. Prólogo. En Missé, M. y Coll-Planas, G. (eds.) El género desordenado. Críticas en torno a la patologización de la transexualidad (pp. 9 -13). Barcelona: Egales.

Cabral, M. (07 de marzo de 2014). Cuestión de privilegio. Suplemento Las 12 Página/12.

Cabral, M. (17 de octubre de 2014a). Leyendo entre líneas. Suplemento Soy, Página/12.

Capicüa. (2014). Aportes para pensar la Salud de personas Trans. Actualizando el paradigma de derechos humanos en salud. Buenos Aires: Capicüa Diversidad.

Cutuli, S. (2010). Apuntes para el análisis de los cambios y continuidades en la organización social y política de las travestis y transexuales en Argentina. Trabajo presentado en Fazendo Genero 9. Florianópolis. Recuperado de http://fazendogenero.ufsc.br/9/resources/anais/1278290057_ARQUIVO_Cutuli,MSoledad-ST69.pdf

Cutuli, S. (2012). Antropología y travestismo. Revisando las etnografías latinoamericanas recientes. Sudamérica. Revista de Ciencias Sociales, 1, 161-181.

Cutuli, S. (2013). Maricas y travestis: repensando experiencias compartidas. Sociedad y Economía, 24, 183-204.

Cutuli, S. y Farji Neer, A. (2016). Mapeando estrategias: iniciativas, oportunidades y dificultades en la implementación de la Ley de Identidad de Género en el ámbito sanitario. Trabajo presentado en XII Jornadas de Debate Interdisciplinario en Salud y Población. Recuperado de http://jornadassaludypoblacion.sociales.uba.ar/ponencias/mesa-10-1-otros-cuerpos-otros-deseos-la-relacio n-entre-el-sistema-medico-y-la-poblacion-lgtb-la-salud-trans-en-foco/

Dalton, B. (2004). Creativity, Habit, and the Social Products of Creative Action: Revising Joas, Incorporating Bourdieu. Sociological Theory 22(4), 603-622.

Deaux K. y Martin, D. (2003). Interpersonal Networks and Social Categories: Specifying Levels of Context in Identity Processes. City University of New York Social Psychology Quarterly, 66 (2), 101-117.

D'hers, V. y Galak, E. (2011). Estudios sociales sobre el cuerpo: practicas, saberes, discursos en perspectiva. Buenos Aires: Estudios Sociológicos. 
Duarte, S. (2009). La Constitución travesti. Buenos Aires: Distal.

Fausto- Sterling, A. (2006). Cuerpos sexuados. Barcelona: Melusina.

Fernández, A. y Siqueira Peres, W. (2013). La diferencia desquiciada. Géneros y diversidades sexuales. Buenos Aires: Biblos.

Fernández, J. (2003). Los cuerpos del feminismo. En Maffia, D. (comp.) Sexualidades migrantes. Género y transgénero (pp. 138-153). Buenos Aires: Librería de Mujeres y Feminaria.

Fernández, J. (2004). Cuerpos desobedientes. Travestismo e identidad de género. Buenos Aires: Edhasa.

Figari, C. y Scribano, A. (comps.) (2009). Cuerpo(s), subjetividade(s) y conflicto(s). Hacia una sociología de los cuerpos $y$ las emociones desde Latinoamérica. Buenos Aires: Fundación Centro de Integración, Comunicación, Cultura y Sociedad - CICCUS.

Fundación Huésped y Asociación de Travestis, Transexuales y Transgéneros de Argentina (ATTTA). (2013). Ley de Identidad de Género y acceso al cuidado de la salud de las personas trans. Buenos Aires. Fundación Huésped y Asociación de Travestis, Transexuales y Transgéneros de Argentina (ATTTA).

Gagnon, J. y Simon, W. (1973). Sexual Conduct: The Social Sources of Human Sexuality. Chicago: USA, Aldine.

Giddens, A. (1995). Modernidad e identidad del Yo. El yo y la sociedad en la época contemporánea. Barcelona: Península.

Hiller, R., Mallimaci, A y Moreno, A. (2011). Chiruzas improvisadas. Conclusiones preliminares a partir de una investigación con travestis. Debate Feminista, 43, 83-112.

Illouz, E. (2009). El consumo de la utopía romántica El amor y las contradicciones culturales del capitalismo. Buenos Aires: Katz.

Illouz, E. (2010). La salvación del alma moderna. Terapia, emociones y la cultura de la autoayuda. España: Katz.

Illouz, E. (2014). Erotismo de autoayuda. Cincuenta Sombras de Grey y el nuevo orden romántico. Buenos Aires: Katz.

Illouz, E. (2016). Por qué duele el amor. Una explicación sociológica. Buenos Aires: Katz.

Jones, D, Figari, C y Barrón López, S. (2012). La producción de la sexualidad. Politicas y regulaciones sexuales en Argentina. Buenos Aires: Biblos.

Lahire, B. (2016). En defensa de la Sociología. Buenos Aires: Siglo XXI

Laqueur, T (1994). La construcción del sexo. Cuerpo y género desde los griegos hasta Freud. Madrid: Cátedra.

Lazzaroni, G. (2015). Combo Trans ¿un lugar en el mundo? Trabajo presentado en XII Jornadas Nacionales de Historia de las Mujeres y VII Congreso Iberoamericano de Estudios de Género. Neuquén.

Liso, V. y Marina, R. (2013). Horacio nunca existió. La Plata: Talleres Propios.

Mansilla, G. (2013). Yo nena, yo princesa. Luana la niña que eligió su propio nombre. Buenos Aires: Universidad Nacional de General Sarmiento.

Medina, C. (2011). El travestismo y los medios. Trabajo presentado en VI Jornadas de Jóvenes Investigadores. Instituto de Investigaciones Gino Germani. Facultad de Ciencias Sociales, Universidad de Buenos Aires. CABA.

Missé, M. y Coll-Planas, G. (eds.) (2010). El género desordenado. Críticas en torno a la patologización de la transexualidad. Barcelona: Egales.

Morán Faundes, J., Sgro Ruata, M. y Vaggione, J. (2012). Sexualidades, desigualdades y derechos. Reflexiones en torno a los derechos sexuales y reproductivos. Córdoba: Ciencia, Derecho y Sociedad.

Namaste, V. (2000). Invisible Lives. The Erasure of Transsexual and Transgendered People. Chicago: University of Chicago Press.

Osborne, R y Guash, O. (2003). Sociología de la sexualidad. Madrid: Siglo Veintiuno.

Pavan, V. (comp.) (2016). Niñez trans. Experiencias de reconocimiento y derecho a la identidad. Los Polvorines: Universidad Nacional de General Sarmiento.

Pecheny, M. (2008). Introducción: Investigar sobre sujetos sexuales. En Pecheny, M., Figari, C., y Jones, D. (2008). Todo sexo es político. Estudios sobre sexualidades en Argentina (pp. 9-17). Buenos Aires: Libros del Zorzal.

Prosser, J. (1998). Second Skins. The Body Narratives of Transsexuality. New York: Columbia University Press. 
López, J. y Paz, L. (2017). El niño Homosexual en la escuela primaria. Tecnologias misotrans del cuerpo escolarizado. Santiago del Estero: Bellas Alas Editorial.

Pedraza Gómez, Z. (2003). Cuerpo e investigación en teoría social. Trabajo presentado en Semana de la Alteridad. Universidad Nacional de Colombia, sede Manizales. Recuperado de http://documentslide.com/documents/cu erpo-e-investigacion-en-la-teoria-social.html

Pérez Fernández-Figares, K. (2010). Historia de la patologización y despatologización de las variantes de género. En Missé, M. y Coll-Planas, G. (eds.) El género desordenado. Críticas en torno a la patologización de la transexualidad (pp. 97-111). Barcelona: Egales.

Ramírez Guzmán, B. (2014). Colonialidade e cisnormatividade. Entrevista con Viviane Vergueiro (Universidade Federal da Bahia). Iberoamérica Social: revista-red de estudios sociales (III) (15-21) Recuperado de http://iberoa mericasocial.com/colonialidade-e-cis-norma-tividade-conversando-com-viviane-vergueiro

Ramírez Mateus, A. (2013). Autorizar una voz para desautorizar un cuerpo: producción discursiva del lesbianismo feminista oficial. Íconos. Revista de Ciencias Sociales 45, 41-57.

Rubin, G. (1989). Reflexionando sobre el sexo: notas para una teoría radical de la sexualidad. En Vance, C. (comp.) Placer y peligro. Explorando la sexualidad femenina (pp. 113-190). Madrid: Revolución.

Sabido Ramos, O y Zabludovsky Kuper, G. (2014). Estudio Introductorio. En Simmel, G. Sociología: Estudios sobre las formas de socialización. México: Fondo de Cultura Económica.

Sabsay, L. (2011). Fronteras sexuales: espacio urbano, cuerpos y ciudadanía. Buenos Aires: Paidós.

Sanzol, C. (2016). Hembra. Cris Miró. Vivir y morir en un pais de machos. Buenos Aires: Editorial Milena Caserola.

Simmel, G. (2014). Sociología: Estudios sobre las formas de socialización. México: Fondo de Cultura Económica.

Sivori, E. (1998). Juan/A. La angustia de vivir en un cuerpo equivocado. Seudohermafroditismo. Una historia de vida. Buenos Aires - Saladillo: Honorable Cámara de Diputados de la Provincia de Buenos Aires.

Solá, J. (2016). La Chaco. Ciudad Autónoma de Buenos Aires: Hojas del Sur.

Stone, S. (1991). The Empire Strikes Back. A Postranssexual Manifiesto. En Epstein, J. y Straub, K.(comps.) Body Guards. The Cultural Politics ofGender Ambiguity (pp. 280-304) New York: Routledge.

Suess, A. (2010). Análisis del Panorama discursivo alrededor de la despatologización trans: procesos de transformación de los marcos interpretativos en diferentes campos sociales. En Missé, M. y Coll-Planas, G. (eds.) El género desordenado. Críticas en torno a la patologización de la transexualidad (pp. 29-54). Barcelona: Egales.

Vacarezza, N. (2012). Una construcción que lleva tiempo. Notas sobre la experiencia temporal del género en el relato de una mujer trans. En Domínguez Mon, A., Méndez Diz, A. M., Schwartz, P. y Camejo, M. (comps.) Usos del tiempo, temporalidades y géneros en contextos (pp. 147-158) Buenos Aires: Antropofagia.

Vacarezza, N. (2013). La performatividad como método. Subjetividades generizadas, cuerpos y lenguaje en la entrevista de investigación. En Campos Pojo, E. y otres (orgs.) A pesquisa no Baixo Tocantis: aspectos, teoricos e metodológicos (pp. 101-112) Curitiba: CRV Editora - Universidad Federal de Pará.

Vacarezza, N. (2015). Feminidades, estilos corporales y performatividad del género. En Chaneton J. (comp.) Modos de vida, resistencias e invención (pp. 43-61). Buenos Aires: La parte maldita.

Vázquez Haro, C. (2012). Configuraciones de identidades trans en los medios gráficos argentinos: nociones identitarias en disputa. Buenos Aires 1998-2005 (Tesis de grado) Facultad de Periodismo y Comunicación Social, Universidad Nacional de La Plata, Argentina.

Weeks, J. (1993). El malestar de la sexualidad. Significados, mitos y sexualidades modernas. Madrid: Talasa.

Weeks, J. (2012). Lenguajes de la sexualidad. Buenos Aires: Nueva Visión.

Zambrini, L. (2007). Cuerpos, indumentarias y expresiones de género: El caso de las travestis de la Ciudad de Buenos Aires. Trabajo presentado en IV Jornadas de Jóvenes Investigadores Instituto de Investigaciones Gino Germani. CABA.

Zambrini, L. (2012). Prácticas travestis. Teorías y debates sobre corporalidades disruptivas. Revista Artemis, 13, $42-61$. 
Zambrini, L. (2013). De metonimias y metáforas sobre géneros y corporalidades travestis en la prensa digital local. Avatares de la comunicación y la cultura, 5, 1-18. Recuperado de http://ppct.caicyt.gov.ar/index.php/avatares/ article/view/3023/2915

\section{Notas}

1 Fvske Menuco o Fisque Menuco es el nombre que le daban los mapuches al paraje donde el ejército fundó el Fuerte General Roca durante la llamada "Conquista del Desierto". Con el paso del tiempo se transformó en la ciudad de General Roca. Esta voz mapuche significa "pantano frío".

2 Con el concepto "trans" nos referimos a aquellas personas cuya identidad de género no se corresponde con el sexo asignado al nacer (no utilizaremos como criterio de inclusión a la categoría "mujeres trans" la implementación de tratamientos médicos o intervenciones quirúrgicas para adecuar la apariencia al género autopercibido). Con este término hacemos referencia a personas transexuales, travestis, transgéneras, cross dresser, no géneros, multigéneros, de género fluído, gender queer y otras autonominaciones vinculadas, que quedan incluidas. Como contraparte, con el concepto "cis" nos referimos a aquellas personas a quienes se les asignó el sexo/género masculino o femenino al nacer y crecen para ser respectivamente hombres y mujeres, es decir que construyen su identidad de género en correspondencia con el sexo de asignación.

3 El proyecto "Trans-Formando Realidades" surgió a partir de la iniciativa de organizaciones trans ante la Universidad Nacional del Comahue. Para conformar un colectivo de trabajo que posibilitara el proyecto, se convocaron a representantes de la Subsecretaría de DDHH de Neuquén, Dirección Provincial de Diversidad de la Provincia de Neuquén, a la Secretaría de Derechos Humanos de la Provincia de Río Negro, y diversas organizaciones trans de Neuquén y Río Negro. El diseño y puesta en marcha del Relevamiento, se propuso y sostuvo, no sin obstáculos, como colectivo y horizontal. En el caso de quien escribe este artículo, fui parte del Relevamiento, en el doble papel de aliade para les integrantes de la Asociación de Trans y Trabajadorxs Sexuales (ATTS) y como Socióloga, en el equipo de asesoramiento técnico-profesional vinculado a a la Universidad Nacional del Comahue. En este contexto, con "aliades" refiero a las personas que luchan por los derechos de las personas trans no binarias, sin serlo.

4 En Argentina, la autopercepción del género se inscribe en la perspectiva de derechos humanos que inspira la Ley 26743, en la que se consagra el derecho a la libre autodeterminación de las personas: al reconocimiento de su identidad de género, al libre desarrollo de su persona conforme a su identidad de género y, en particular, a ser identificada de ese modo en los instrumentos que acreditan su identidad respecto de el/los nombre/s de pila, imagen y sexo con los que allí es registrada. Por identidad de género se entiende a la vivencia interna e individual del género tal como cada persona la siente, la cual puede corresponder o no con el sexo asignado al momento del nacimiento, incluyendo la vivencia personal del cuerpo. En el artículo $2^{\circ}$ de la Ley 26743, queda expuesto que la construcción identitaria no supone correspondencia alguna con un anclaje o exigencia de corte biológico corporal.

5 En este trabajo se utilizó una muestra intencional construida a través de la técnica "bola de nieve", partiendo de un listado provisorio de la población en cuestión, elaborado por las organizaciones trans. Luego, buscamos ampliar —a través de las entrevistas - el grupo de potenciales encuestades, intentando alcanzar a la totalidad de población. El único criterio que se utilizó para considerar a una persona como parte de la población objetivo fue su género autopercibido. La muestra quedó conformada por un total de 133 personas trans, de 16 años y más, de las localidades de Neuquén (80), Plottier (5), Fiske Menuko (30), Ingeniero Huergo (10) y Villa Regina (8). Obtuvimos una tasa de respuesta del $67 \%$ comprendido por 69 mujeres trans y 20 varones trans.

6 Con "pasar" les encuestades se refieren a que no resulte visible su condición de persona trans y por lo tanto puedan ser leídas socialmente como personas cis.

7 Los "momentos decisivos" refieren a tiempos en que los acontecimientos se presentan de tal manera que el individuo se encuentra en una encrucijada de su existencia. Se trata de coyunturas que quiebran la actitud de dejar que las cosas “sigan como están”.

8 En Argentina, en el año 2012 se sanciona la Ley 26743 de Identidad de género, luego de una sostenida lucha por parte de organizaciones y movimientos sociales. La ley sancionada plantea la ruptura con el paradigma biomédico en la noción de identidad autopercibida. Esta ley reconoce que la construcción del derecho humano a la personalidad jurídica es un proceso propio de cada persona, autónomo del reconocimiento del Estado. En el artículo $2^{\circ}$ se da una definición abierta de lo que es la identidad de género, cómo se percibe. Este es un concepto que aparece como trascendente, en tanto es abierto. Es decir, no solo tiene que ver con esta época histórica (como todos los conceptos que se establecen en las leyes tienen que ver con un contexto y es una foto del momento de la sociedad) sino que "es un concepto que permite que dentro de veinte años por 'identidad de género' se pueda entender otra cosa; y así y todo, tiene que seguir siendo reconocida" (intervención de la Abogada Jorgelina Montero en el panel del Encuentro Académico Activista 
denominado "Transitando realidades a partir de la Ley de Identidad de Género" realizado en el marco de la Cátedra Libre de Géneros, Sexualidades y Derechos Humanos La Libre de Géneros de la Facultad de Derecho y Ciencias Sociales de la Universidad Nacional del Comahue, octubre de 2015)

9 No desconocemos que algunas personas trans no se reconocen en las identidades binarias hombre-mujer y que buscan construir un género fluido que no se encuadre en las categorías sociales disponibles. Se definen como no binaries.

10 Nos referimos a la manera en que el sentido de una práctica es establecido y juzgado por un grupo y la "acción apropiada" resulta de un acuerdo — negociado y temporal - de ese grupo (King, 2000)

11 La "creatividad" se utiliza aquí redefinida como la adaptación necesaria de las prácticas habituales a contextos específicos de acción (Dalton, 2004)

12 Incluimos a mujeres trans con deseos heterosexuales, así como a aquellas que manifiestan elecciones vinculadas a otras mujeres y/o identidades no normativas.

13 Con "porteño" aludimos a lo relativo a la Ciudad Autónoma de Buenos Aires (Capital de Argentina) y/o a sus habitantes 